\title{
ASPECTOS TEÓRICOS DO PENSAMENTO HISTÓRICO DE QUENTIN SKINNER
}

\author{
Marcos Antônio Lopes* \\ marcos.lopes@pq.cnpq.br
}

RESUMO Após retratar o surgimento da Escola histórica do pensamento político de Cambridge, o foco da análise é centrado no desenvolvimento de alguns dos pressupostos teóricos elaborados por um de seus mais expressivos cultores: Quentin Skinner. Sem me ocupar com a exposição de "modelos alternativos" de interpretação de textos ou com a análise das críticas dirigidas ao contextualismo linguístico, passo em revista apenas os elementos que compõem o cerne da teoria interpretativa de textos políticos, conforme formulada pelo historiador inglês. Nesse sentido, discuto os pressupostos que o autor, ainda hoje, parece julgar úteis àqueles que se ocupam em perceber, nos clássicos da política, as diferenças e as singularidades que apartam de nós sistemas de crenças e vocabulários normativos de sociedades politicas perdidas em tempos remotos.

Palavras-chave Teorias da interpretação de textos, historicidade das ideias, linguagem e ação política, Quentin Skinner.

ABSTRACT After depicting the birth of the Cambridge historical school of political thought, the focus of the analysis is placed on the development of some theoretical assumptions created by one of its most representative followers: Quentin Skinner. Unconcerned with the exposition of "alternative models" for text interpretations or with the analysis of the criticism directed to

* Professor de Teoria Política na Universidade Estadual de Londrina. Pesquisador do Centro Nacional de Desenvolvimento Científico e Tecnológico/CNPq (Bolsista Produtividade em Pesquisa). Artigo recebido em 4/03/2010 e aprovado em 10/12/2010.

KRITERION, Belo Horizonte, nº 123, Jun./2011, p. 177-195. 
linguistic contextualism, this study revises the key elements of the interpretative theory of political texts, according to the English historian. In this sense, we discuss the assumptions that the author, even today, seems to deem useful to those who are interested in noticing in classic Politics the uniqueness which set us apart from the system of beliefs and normative vocabulary of the political societies lost in remote times.

Keywords Text interpretation theories, historicity of ideas, language and political action, Quentin Skinner.

Uma insatisfação que sinto diante do tradicional método "textualista" é que, embora seus expoentes em geral afirmassem estar escrevendo uma História da Teoria Política, raras vezes o que nos apresentaram pôde ser considerado, de fato, História.

Quentin Skinner

Quando falo de intencionalidade dos autores, não estou me referindo ao significado dos textos ou elocuções, mas ao significado do ato de escrever o texto ou proferir uma elocução. Na verdade, minha teoria da interpretação, diferentemente de outras teorias mais tradicionais, dá grande ênfase ao que chamo de atos linguísticos.

Quentin Skinner

Neste ensaio bibliográfico aplico-me a comentar alguns aspectos que considero centrais no pensamento histórico de Quentin Skinner. Não tomo como propósito acompanhar as alterações de suas visadas teóricas desde o aparecimento dos primeiros ensaios de sua autoria, por volta dos fins dos anos 1960 e inícios dos 70, até os trabalhos produzidos mais recentemente. Em cerca de quarenta anos de intensa atividade intelectual é mesmo presumível que as técnicas hermenêuticas propostas pelo historiador inglês tenham passado por alterações mais ou menos sensíveis e que, em alguns pontos, o autor tenha até deixado de concordar consigo mesmo. ${ }^{1}$ Entretanto, é igualmente natural que um núcleo de pressupostos tenha resistido à ação transformadora do tempo, permanecendo como eixo das concepções em relação às quais o autor manteve-se fiel, o que lhe permitiu preservar-se vivo no interior do rico e va-

1 No primeiro volume de Visions of Politics, coletânea de 10 ensaios teóricos, percebe-se as variações das perspectivas autorais ao longo de mais de trinta anos. Organizada por Skinner, ele mesmo se encarrega de informar ao leitor, em notas de rodapé, os pontos em que sua visão atual não mais coincide com os princípios afirmados à época da primeira redação dos artigos. Cf. SKINNER, Quentin. Visions of Politics. Cambridge/UK: Cambridge University Press, 2002. 
riado campo teórico de sua especialidade. É este "núcleo duro" - apanhado em meio à leitura de seus textos reatualizados e de seus depoimentos mais recentes acerca das técnicas interpretativas das obras de pensamento -, o objeto central desta análise.

No artigo "Razões da Filosofia Política", que integra o livro de ensaios Teoria Geral da Política, Norberto Bobbio examinou o clima de tensão existente em alguns campos limítrofes das Ciências Humanas. Nesse texto, o filósofo italiano afirmou que "As nem sempre boas relações, para não dizer a desconfiança recíproca, entre historiadores das doutrinas políticas e filósofos da política são efeito de incompreensíveis (perdoem o trocadilho) incompreensões, quando não de completos mal-entendidos". ${ }^{2}$ Há nesta ironia conteúdo para vastas reflexões. E é nesse ponto que surgem diversas dúvidas, como as expostas por John Horton, acerca da forma "mais adequada" e da real importância de se estudar os chamados textos clássicos da Teoria Política. Para reconstruir o significado histórico dos textos seria preciso estudá-los por uma perspectiva a princípio histórica, empregando os métodos e práticas do historiador? Ou dever-se-ia focá-los por um prisma filosófico como obras que pretendem oferecer verdades gerais acerca da natureza da vida e da organização política com vistas a avaliar a força de seus argumentos, a revelação de suas suposições e outras coisas do gênero ${ }^{3}$ Segundo a concepção de alguns historiadores do pensamento político, a Teoria Política clássica pode ser adequadamente estudada lançando-se mão do método histórico. Mesmo especialistas de relevo no campo da Teoria Política, como o filósofo teuto-americano Leo Strauss, que tomaram o "partido da intemporalidade" das ideias dos grandes pensadores, reconheceram a necessidade do emprego de uma abordagem histórica dos textos políticos. ${ }^{4}$ Mas, ainda que se tente

2 BOBBIO, Norberto. Razões da filosofia política. In: ——. Teoria Geral da Política: a filosofia política e as lições dos clássicos. Rio de Janeiro: Campus, 2000, p. 95.

3 Cf. HORTON, John. La filosofía política y la política. In: LEFTWICH, Adrien. (Org.). Qué es la política? México: Fondo de Cultura Económica, 1992, p. 201.

4 "I assumed that political philosophy, as an essentially non-historical pursuit, is today in need of a critical study of its history; that such a critical history presupposes that one understand the great thinkers of the past as they understood themselves; that the history of political philosophy requires an adequate division into periods; an that only such a division can be considered adequate as corresponds to the self-consciousness of the actors, i.e of great political philosophers". STRAUSS, Leo. The Political Philosophy of Hobbes. Its Basis and Its Genesis. Chicago: The University of Chicago Press, 1984 (ed. orig. 1952), p. XV. Amplas análises das visadas teóricas do notável filósofo Strauss foram desenvolvidas por: BLOOM, Allan. Leo Strauss. In: —. Gigantes e anões. São Paulo: Best Seller, s.d., p. 205ss; MILLER, Eugene. Leo Strauss. 
dividir este problema em partes, para oferecer uma resposta mais ordenada e rigorosa, a tendência é a de elevar a complexidade do debate teórico. Isso porque são remotas as possibilidades de consenso sobre o que é ou o que deve ser a referida abordagem histórica no estudo da Teoria Política e em quais operações intelectuais ela consiste. O historiador inglês Quentin Skinner observou o grau de complexidade da questão ao afirmar que "Há tantos tipos de História quantas razões sérias para estar interessado no passado, e tantas diferentes técnicas de pesquisa histórica quantos métodos racionais de seguir esses interesses". 5

O contextualismo linguístico professado por Quentin Skinner desenvolveu-se a partir dos fins dos anos 1960 e inícios dos 70. As fontes constitutivas que estabeleceram os seus marcos teóricos são bem diversas. Dentre as influências mais diretas contam-se, além do pensamento histórico de Robin George Collingwood, a filosofia da linguagem de Ludwig Wittgenstein e de John Langshaw Austin, ${ }^{6}$ bem como várias outras "escolas" contemporâneas das Ciências Humanas. Naqueles anos 60 os artigos teóricos de Skinner despontaram como um conjunto de considerações críticas no interior de um gênero tradicionalmente conhecido nos países de língua inglesa como História do Pensamento Político. ${ }^{7}$ Nas pegadas de Collingwood, ou seja, procurando repensar o pensamento dos autores do passado, o contextualismo linguístico foi responsável por reflexões polêmicas no plano das teorias da interpretação de textos frequentadas pelos historiadores da Filosofia. Como se sabe, a História collingwoodiana é uma forma de contextualismo radical das ideias, fundada na aposta de que há uma identidade fundamental e/ou uma contiguidade natural entre o sujeito que interpreta e o objeto alvo de uma análise. Sujeito e objeto são, por assim dizer, manufaturas humanas, artefatos

In: DE CRESPIGNY, Anthony \& MINOGUE, Kenneth. Filosofia Política Contemporânea. Brasília: Editora da UnB, 1982, p. 73ss; TARCOV, Nathan. Leo Strauss y la historia de la filosofía política. In: STRAUSS, Leo \& CROPSEY, Joseph. Historia de la filosofia política. México: Fondo de Cultura Económica, 1996, p. 851ss.; e KERVÉGAN, Jean-François. Leo Strauss. In: ——. HUISMAN, Denis. Dicionário dos filósofos. São Paulo: Martins Fontes, 2002, p. 949ss.

5 SKINNER, Quentin. A liberdade e o historiador. In: ——. Liberdade antes do liberalismo. São Paulo: Editora Unesp, 1999, p. 88.

6 Para uma visão panorâmica das contribuições específicas de Wittgenstein e Austin leia-se, respectivamente, os verbetes homônimos de Paul Gochet e Grahame Lock em: HUISMAN, Denis. Dicionário dos filósofos. São Paulo: Martins Fontes, 2002.

7 Sem que se tenha de enfrentar os longos ensaios teóricos de Quentin Skinner em inglês, é possível "apanhar" o sentido mais amplo do contextualismo linguístico por ele professado nos textos introdutórios de alguns de seus livros publicados no Brasil. Para a exposição do chamado "método" do contextualismo linguístico de Cambridge, a partir da argumentação de um de seus próprios praticantes, consulte-se os seguintes textos: POCOCK, John. Introdução: o estado da arte. In: ——. Linguagens do ideário político. São Paulo: Edusp, 2003; e POCOCK, John. O conceito de linguagem e o métier d'historien. In: ——. Linguagens do ideário político. 
feitos do mesmo material. Ora, considerou Collingwood, tudo aquilo que o homem realiza é feito em relação aos outros homens iguais a ele, que são como ele. Há, portanto, uma "relação colaborativa" entre o pensador e o leitor, porque ambos pertencem a uma mesma comunidade, a dos seres falantes. Para Collingwood, interpretar era uma operação que consistia em introduzir-se na cabeça dos autores do passado e olhar para as suas circunstâncias singulares tentando vê-las com o olhar deles próprios. Radicalizando um pouco, isso é algo assim como disse Nietzsche: "Só há um meio de compreender a tragédia grega: ser Sófocles". ${ }^{8}$ Isso é também como afirmar: mais do que entender um pensamento, é possível apropriar-se dele como se fosse nosso próprio pensamento. ${ }^{9}$ A referida identidade fundamental de sujeito e objeto expressa pelo pensamento asseguraria a realização do processo interpretativo. Segundo Collingwood, a interpretação das ideias passadas seria possível porque, escapando da ação corrosiva do tempo, o pensamento tornar-se-ia matéria acessível em diferentes épocas pois, para além de um sentido do texto, poderia revelar-nos uma intenção, ou seja, que "efeitos" sociais o autor pretendia produzir com o seu escrito. O contextualismo de Skinner deriva diretamente dessa linhagem de interpretação. A dívida ou os vínculos deste historiador para com o gênero de História professado por Collingwood podem ser identificados em muitas passagens e/ou confissões de sua extensa obra, como a que segue: "Ainda me recordo de quão impressionado fiquei ao ler pela primeira vez a Autobiografia de R. G. Collingwood, onde ele afirma que a história de todas as ramificações da filosofia carece de um objeto estável, na medida em que as perguntas bem como as respostas mudam continuamente". ${ }^{10}$

O que passou a ser conhecido como "escola histórica de Cambridge da Teoria Política" teve em Peter Laslett o seu primeiro expoente já nos anos 1940. Ele foi, por assim dizer, o líder intelectual de uma geração posterior à sua própria. A título de ilustração das contribuições de Laslett para a História

8 NIETZSCHE, F. "Fragmentos póstumos e aforismos". In: ——. Escritos sobre História. Rio de Janeiro/São Paulo: Editora PUC-Rio/Edições Loyola, 2005, p. 289.

9 E o autor vai além, ao afirmar que, dessa mesma maneira, até as sensações alheias podem ser sequestradas. O seu exemplo é a emoção despertada em nós pelos poetas: "Quando alguém lê e entende um poema, ele não está simplesmente entendendo a expressão do poeta de suas próprias emoções, isto é, das emoções do poeta; o que o ouvinte está expressando são suas próprias emoções, pelas palavras do poeta, que assim se tornaram suas próprias palavras. Como afirma Coleridge, sabemos que um homem é um poeta pelo fato de que ele nos faz poetas". COLLINGWOOD, R.G. citado por RIDLEY, Aaron. R.G. Collingwood. São Paulo: Editora Unesp, 2001, p. 53.

10 SKINNER, Quentin. A liberdade e o historiador. In: - Liberdade antes do liberalismo. p. 84. Provavelmente, a passagem à qual se refere Skinner na Autobiografia de Collingwood é a seguinte: "... a História da Teoria Política não é a História de diferentes respostas dadas a uma e mesma questão, mas a História de um problema mais ou menos em mudança constante, cuja solução estava mudando com ele". COLLINGWOOD, R.G. citado por GUNNEL, John. Teoria Política. Brasília: Editora da UnB, 1981, p. 91. 
do Pensamento Político, foi ele quem descobriu que a mais importante obra política de John Locke, o Tratado sobre o governo civil, havia sido concebida e escrita muitos anos antes da Revolução Gloriosa de 1688-89. O fato é que se formara uma longa tradição, sedimentada há mais de dois séculos, que dava por líquido e certo que o texto de Locke era posterior à queda de Jaime II, e que fora escrito com a finalidade explícita de legitimar a ascensão de Guilherme de Orange. ${ }^{11}$ A partir da reflexão crítica de Quentin Skinner, que trabalhou sob a orientação de Laslett em seus primeiros anos em Cambridge, a História do Pensamento Político, gênero histórico com sólida tradição intelectual nos Estados Unidos e na Inglaterra desde os inícios do século XX, conheceu um notável impulso de renovação. Alguns textos teóricos escritos a partir dos anos 1960 por historiadores ingleses da Teoria Política como John Dunn, John Pocock e o próprio Skinner, acabaram por desencadear debates que foram responsáveis pela circulação de novos pressupostos no plano das teorias interpretativas dos textos políticos. E a obra crítica desses autores deu origem a uma discussão que ainda não se esgotou.

Em sua origem, essa corrente revisionista das teorias interpretativas de textos políticos atacou algumas das concepções ainda hegemônicas na cena historiográfica daqueles anos, abalando convicções há muito consolidadas. No alvo de sua crítica estavam, principalmente, a carência de historicidade e o pragmatismo imediatista predominantes na História do Pensamento Político anglo-americana. ${ }^{12}$ Historiadores como Skinner, autor dos primeiros e mais enérgicos ensaios teóricos em defesa de um novo programa de pesquisa, esgrimiram contra uma História do Pensamento Político que ainda se ocupava em explorar aspectos anacrônicos, simplificadores ou mesmo insustentáveis à luz dos avanços da pesquisa histórica como, por exemplo, a equívoca ideia da "tradição" filosófica do Ocidente. Para ele, era difícil conceber que os grandes

11 Acerca do contextualismo de Cambridge, segundo a concepção de Laslett, há dois textos exemplares. Ambos são estudos introdutórios ao pensamento político de Locke e Filmer e, como tais, bastante reveladores da hermenêutica do historiador inglês. Ver: LASLETT, Peter. "Patriarchalism in Seventeenth Thinking. Filmer and his Contemporaries". In: —_. (Org.). Patriarcha and Other Political Works of Sir Robert Filmer. Oxford: Basil Blackwell, 1949, p. 20ss.; e LASLETT, Peter. Apresentação. In: LOCKE, John. Dois tratados sobre o governo. Martins Fontes, 2001.

12 Por sua vez, essa "História presentista" havia lutado por décadas em prol do reconhecimento da própria legitimidade dos estudos históricos em Teoria Política. Entre os anos 1930-50 ela esgrimira contra a Ciência Política behaviorista defendida por David Easton, que tentara deslegitimá-la como campo de pesquisa. Um historiador norte-americano da Teoria Política explica a questão: "The status of political theory has been a perennial subject of controversy. In recent years the debate in the United States has focused upon methodological considerations. This was probably inevitable, given the intention of a sizable group to transform the study of politics into a 'science of politics modelled after methodological assumptions of the natural sciences'. In pointing to the model of scientific inquiry as the appropriate one for political and social science". WOLIN, Sheldon. "Paradigms and Political Theories". In: - KING, Preston \& PAREKH, B.C. (Org.). Politics and Experience. Cambridge: Cambridge University Press, 1968, p. 125. 
textos da cultura filosófica possuiriam um status especial de trans-historicidade porque foram manufaturados por algumas mentes brilhantes do passado, mentes que teriam o dom de cometer sortilégios como o de transformar os assuntos dos quais se ocuparam em temas eternos e, portanto, obrigatórios tanto para a juventude grega ao tempo de Platão quanto para os estudantes nas metrópoles norte-americanas e inglesas nos meados do século XX. Se as questões filosóficas expostas por tais mentes superiores fossem de fato eternas e ubíquas, tal foco analítico permitir-nos-ia imaginar que Maquiavel, que Hobbes, ou mesmo que qualquer outro grande pensador, em meio a seus transes de genialidade filosófica, poderiam ter premeditado, por exemplo, o que deveriam escrever que pudesse ser digno de ocupar utilmente a cabeça de leitores que viriam ao mundo quatro ou cinco séculos depois deles.

A crítica à ideia de uma "tradição" como "circuito fechado" na história da filosofia política clássica, na qual os grandes autores estariam integrados em contínuo e aberto diálogo uns com os outros, foi desenvolvida nos seguintes termos: "Um cânone de textos principais era amplamente visto na época como o único objeto apropriado de pesquisa na História do Pensamento Político. A razão, alegava-se, é que esses textos podem por definição ser considerados como indo ao encontro de um conjunto de perenes questões definitivas do próprio pensamento político. Era amplamente assumido que, se o estudo histórico da moral ou da teoria política deve ter algum traço característico, este terá de assumir a forma de extrair dos textos clássicos quaisquer insights que eles possam nos oferecer sobre questões gerais da sociedade política na época presente. Eles estão lá para serem apropriados e postos para trabalhar". ${ }^{13}$ Uma das orientações de Skinner era para que os historiadores da Teoria Política não se concentrassem numa galeria de autores clássicos supostamente em diálogo. ${ }^{14}$

Em vez de tentar acompanhar uma animada e inteligente conversação desenvolvida por sucessivas gerações de sábios pensadores, ${ }^{15}$ os historiadores

13 SKINNER, Quentin. "A liberdade e o historiador". In: _. Liberdade antes do liberalismo. p. 83s.

14 "O valor de nossos estudos era tido como o de nos capacitar a revelar o que é de interesse perene numa grande sequência de textos clássicos". SKINNER, Quentin. "A liberdade e o historiador". In: ——. Liberdade antes do liberalismo. p. 86s.

15 Dentre os que assim crêem destaco um historiador norte-americano, discípulo de Strauss: "A filosofia tem sido, no seu auge, um diálogo amplo entre os grandes, não importa o quanto estejam separados no tempo". BLOOM, Allan. "O estudo dos textos". In: —. Gigantes e anões, p. 289. Uma tal visada teórica talvez permita ler Maquiavel e enxergar nele não um cidadão da república aristocrática de Florença na época do Renascimento, mas sim um personagem contemporâneo de todas as épocas. A essa alternativa, prefiro crer na ressalva feita pelo historiador inglês Peter Burke: “... is the function of intellectual historians to warn their own generation of the interpretation of the dissortions involved in this reinterpretation of the past, in treating Montaigne (like Shakespeare, or Dante) as our contemporary. We need to remember that he is not one of us". BURKE, Peter. Montaigne. Oxford: Oxford University Press, 1994, p. 73. 
da Teoria Política deveriam avaliar os textos dos grandes autores nas tradições filosóficas específicas em que surgiram. Isso porque a dita sabedoria filosófica em afinado concerto ao longo de dois milênios e meio de história não passava de mais uma dentre muitas mitologias, ${ }^{16}$ de uma patranha inventada pelos golpes de criatividade de certos historiadores mais imaginativos, e logo admitida por numerosos outros historiadores desprovidos de sentido histórico. Ora, considerou Skinner, a ideia da tradição filosófica (o circuito fechado das grandes mentes) era uma construção intelectual concebida por historiadores do século XX para tentar compreender as complexidades do próprio tempo de incertezas em que viviam. Movidos por impulsos presentistas, esses historiadores desejavam estabelecer vinculações entre os vários livros por eles considerados como clássicos da Teoria Política para, das culminâncias do saber alcançado por tal procedimento, extrair as lições necessárias e aplicá-las às circunstâncias de seu mundo. A percepção do autor em foco, e de uma série de outros historiadores que rejeitaram o mito da tradição, era a de que nada havia que comprovasse qualquer relação verdadeiramente histórica entre os ditos grandes livros da referida tradição ocidental de Filosofia Política. ${ }^{17} \mathrm{E}$, sendo assim, nada poderia haver de mais equivocado de um ponto de vista histórico que a "atitude prática" adotada tanto como instrumento de análise do tempo presente quanto como função legitimadora da relevância dos estudos históricos de tal gênero.

Ao invés de focar a História do Pensamento Político como a pesquisa de continuidades, de sequências de grandes ideias impactantes e, portanto, "utilizáveis", o melhor ângulo a ser captado pelo historiador seria aquele de uma História como investigação das linguagens políticas, ângulo que permitiria a análise das sociedades passadas em relação dialógica consigo mesmas. A ideia era identificar os horizontes historicamente variáveis da política, portanto, não absolutos, para então penetrar nos mundos intelectuais perdidos no tempo e tentar recuperar os sentidos que os escritores políticos formaram de si mesmos, de seu tempo, de sua sociedade. Os inventores da

16 Skinner utiliza largamente esse conceito em seu artigo intitulado "Meaning and Understanding in the History of Ideas", publicado originalmente na revista History and Theory, no ano de 1969. Esse texto foi republicado na coletânea-debate de James Tully. Cf. TULLY, James. (Org.). Meaning and Context. Quentin Skinner and his critics. Cambridge: Polity Press/Basil Blackwell, 1988. Além de textos do autor, o livro de Tully traz uma série de ensaios críticos às visadas teóricas de Skinner, e algumas respostas que ele ofereceu a seus comentadores. Próximo a esse espírito é a obra concebida por historiadores espanhóis. Cf. BOCARDO CRESPO, Enrique. (Org.). El giro contextual. Cinco ensayos de Quentin Skinner, y seis comentarios. Madrid: Editorial Tecnos, 2007.

17 Este aspecto é precisamente acentuado pelo historiador norte-americano David Harlan em seu longo ensaio sobre a História Intelectual. Cf. HARLAN, David. "A história intelectual e o retorno da literatura". In: RAGO, M. \& GIMENES, R. (Org.). Narrar o passado, repensar a história. Campinas: IFCH, 2000, p. 45. 
ideia de uma tradição filosófica autocentrada em questões perenes recusaramse a pensar na possibilidade de um retorno ao passado por considerarem que os seus dificultosos pontos cegos, que as suas embaraçosas zonas de sombras constituíam-se numa empresa difícil e desprovida de fins úteis. Estudar ideias que estavam ainda em fase de processamento nas sociedades já desfeitas pela ação do tempo seria o equivalente a uma cansativa viagem, sem garantias de real proveito. Nesse sentido, tal gênero de História atinava apenas com a possibilidade de identificar consequências instrumentais para emprego seguro na superfície clara e cômoda do presente, quando as grandes ideias filosóficas do passado já haviam se tornado doutrinas bem estabelecidas e, por fim, pudessem ser empregadas na orientação das melhores causas da atualidade. Daí, por exemplo, a preferência pelo estudo das ideias de liberdade do liberalismo, e o descarte da derrotada ideia de liberdade conforme expressa pela teoria neo-romana. ${ }^{18}$

De fato, o primeiro obstáculo a ser transposto por essa nova História do Pensamento Político seria o da consagrada ideia da tradição. Para Skinner, aquilo a que se denominara tradição era apenas uma convenção acadêmica que procurava destacar artificiosamente a série dos grandes pensadores estabelecendo entre si uma prosa animada. A ideia da tradição prestava-se também como uma teleologia retrospectiva, espécie de paradigma regulador para o estudo da Teoria Política clássica porque, além dos diálogos entre autores, estabelecia suposições como a de que o sentido dos sistemas filosóficos, de Platão e Aristóteles a Rousseau e Hegel, foi o de projetar os valores e amadurecer as instituições que pudessem vicejar nas sociedades democráticas e liberais do século XX. Como teleologia retrospectiva, a História do Pensamento Político deveria incrementar a formação dos cidadãos para a vida plena nessas sociedades, oferecendo-lhes algumas armas teóricas para estabelecerem crítica eficaz contra os valores malsãos propugnados pelos Estados totalitários. Ao longo dos anos 1930-50, os historiadores que aceitaram a ideia da tradição como uma entidade histórica autônoma ou mesmo como uma unidade e/ou totalidade natural, acabaram por referendar um pressuposto prático: havia um fim educativo nessas grandes filosofias e seu propósito era o de explicar o tempo presente à luz dos mestres do passado. Entretanto, o fato evidente é que o interesse centrado nos debates de cúpula dos maiorais da sabedoria filosófica pouco ou nada revelava acerca dos "consumidores" contemporâneos ou mesmo dos críticos primitivos das suas ideias políticas que, como seria

18 Cf. SKINNER, Quentin. "A teoria neo-romana dos Estados livres”. In: —_. Liberdade antes do liberalismo. p. 16ss. 
razoável supor, foram concebidas no interior de uma cápsula comum de tempo. De mais a mais, afirmar algo tão esquemático como as ideias de tal autor serem desdobramentos ou prefigurações das de outro dado autor nada ensinava que fosse "História verdadeira" (expressão de Montesquieu). Argumentos como esses engrossaram a crítica de uma falsa História do Pensamento Político que primava pela carência de interação entre concepções filosóficas e sociedade. ${ }^{19}$ Ao analisar falhas de tal natureza presentes na "História das ideias descarnadas" (expressão de Lucien Febvre), o contextualismo linguístico inglês deu relevo à crítica do divórcio entre as ideias e o mundo real, em níveis tão importantes como os das condições de emergência, de circulação e de enraizamento de uma obra de pensamento político.

Para críticos como Quentin Skinner, nesse gênero de História não era possível identificar um interesse real em apreender as grandes obras de pensamento a partir do sentido histórico singular que cada uma possuía. Desse modo, o autor se colocou contra a "atitude prática" que se voltava para a utilização das ideias passadas como preparação do exercício da cidadania nas sociedades contemporâneas. A referida atitude prática é assim explicada por Michael Oakeshott: "O homem prático lê o passado de trás para frente. Seu interesse situa-se apenas no plano de um conhecimento de acontecimentos que se prestem a ser relacionados com ações no tempo presente. Ele organiza o passado para explicar o mundo atual, para justificar sua própria realidade, para tornar seu mundo mais tranquilo, menos incerto". ${ }^{20}$

Historiadores como Skinner julgaram que faltava algo de mais substantivo às tradicionais Histórias do Pensamento Político: historicidade, por exemplo. Seria necessário, portanto, superar pressupostos falseadores que faziam dos mestres do passado os guias do tempo presente. Em vez de selecionar "matérias úteis" ou "utilizáveis", a interpretação contextualista preocupou-se em indagar acerca de formas mais adequadas para se alcançar o

19 Já em fins dos anos 1960 outro historiador inglês demonstrava insatisfação da mesma natureza ao criticar as análises filosóficas brilhantes, mas realizadas em níveis etéreos. "O que é muito necessário atualmente", afirmava W. Greenleaf, "não é mais o insight ou exegese textual, mas simplesmente mais pesquisa". GREENLEAF, W. "Hobbes: o problema da interpretação". In: —. QUIRINO, C.G. \& SOUZA, M.T.S. (Org.). O pensamento político clássico. São Paulo: T.A. Queiroz, 1992. p. 74. (A versão original do artigo é de 1968).

20 "The practical man reads the past backwards. He is interested in and recognizes only those past events which he can relate to present activities. He looks to the past in order to explain his present world, to justify it, or to make it a more habitable and a less mysterious place". OAKESHOTT, Michael. "The Activity of being an Historian". In: —. Rationalism in Politics and other essays. Londres: Methuen \& Co., 1967, p. 153. Vastas considerações acerca do pensamento histórico do filósofo inglês foram feitas por: WALSH, W.H. "The pratical and the historical past”. In: —. KING, Preston \& PAREKH, B.C. (Org.). Politics and Experience. Cambridge: Cambridge University Press, 1968, p. 5ss; e DRAY, Willian H. "Michael Oakeshott's theory of history". In: —. KING, Preston \& PAREKH, B.C. (Org.). Politics and Experience. p. 19ss. 
sentido original de um texto: aquele que o próprio autor havia concebido no tempo em que escreveu. Não se tratava mais de realçar atitudes pragmáticas como a "do quê" estudar na História do Pensamento Político para extrair "fins lucrativos", quero dizer, para alcançar finalidades práticas. Tratava-se muito antes de estabelecer critérios eficazes do "como" estudar uma obra de pensamento, do "como" formular a um objeto por vezes perdido em passado distante perguntas de uma maneira pertinente. O objetivo era tornar a História Intelectual um tipo de investigação fundada na própria diferença essencial dos tempos históricos. "Em particular", afirma o historiador em foco, "talvez verifiquemos que a aquisição de uma perspectiva histórica nos ajude a tomar uma certa distância de alguns de nossos pressupostos e hábitos de pensamento atuais, e, quem sabe, até a reconsiderá-los. O estudo do passado não precisa ser menos instrutivo quando desvenda contrastes, em vez de continuidades com o presente". ${ }^{21}$ Como se apercebera um importante filósofo de uma geração anterior, Michael Oakeshott, os textos antigos de fato não podem ser espelhos refletores de nossos preconceitos. Ora, considera Skinner, os estranhos mundos de Maquiavel, de Hobbes, enfim, dos autores canônicos da Teoria Política em geral, oferecem aspectos bem mais interessantes se nos valermos de atitudes, digamos assim, mais flexíveis, quando os confrontarmos.

Como já foi observado, a obra de Skinner acentua o reconhecimento da irrelevância de uma filosofia da história subjacente à civilização ocidental. O contextualismo linguístico por ele defendido colocou sob suspeita a chamada "filosofia perene", perspectiva um pouco claudicante daqueles especialistas que tendiam para a articulação muitas vezes descabida dos problemas do presente com a interpretação do passado. De fato, uma das questões fundamentais enfrentadas pelo contextualismo linguístico foi ter percebido que, das duas uma: ou a história das ideias políticas se engessava de vez na procura incessante e equivocada do sentido atual e do valor prático da tradição clássica, que de Platão a Marx parecia formar um circuito fechado de interlocutores privilegiados em contínuo diálogo; ou assumia "atitude histórica" reconhecendo a natureza incontornavelmente datada de suas fontes. Desse modo, a História do Pensamento Político deveria apreender as reais preocupações de um Aristóteles, de um Maquiavel, de um Rousseau, de um Montesquieu, por exemplo, naqueles elementos que revelassem à posteridade as intenções de um escritor político confrontando-se com as questões que foram próprias de sua época. Para o autor, 
Não podemos esperar atingir esse nível de compreensão estudando tão-somente os próprios textos. A fim de percebê-los como respostas a questões específicas, precisamos saber algo da sociedade na qual foram escritos. E, a fim de reconhecer a direção e força exatas de seus argumentos, necessitamos ter alguma apreciação do vocabulário político mais amplo de sua época. ${ }^{22}$

Tais propósitos parecem demonstrar que não bastará ler atentamente um texto até devassá-lo em suas filigranas mais sutis. Para alcançar o sentido autoral provável numa obra de pensamento político seria necessário também conhecer os seus elementos geradores. Isso para dizer que a compreensão de O Príncipe ou do Leviatã, por exemplo, passará pelo esclarecimento do vocabulário normativo, das tensões sociais, dos conflitos políticos e ainda pelo alcance de toda uma gama de elementos que fizeram as histórias italiana e inglesa nos séculos XVI e XVII. Essa História do Pensamento Político proposta pelos contextualistas ingleses parece reconhecer bem o valor de um arrazoado que nunca perderá seu realismo: um autor é sempre um autor, acompanhado de suas circunstâncias. Assim sendo, seria necessário diminuir em muito a ênfase de uma História interessada apenas em ouvir ecos do passado no presente. Ao mesmo tempo, seria necessário buscar uma interpretação do passado que tomasse como matérias-primas de base a linguagem e a cultura, isto é, o texto e o contexto. Nesses aspectos residiria a atitude teórica capaz de aproximar o historiador de uma compreensão histórica dos discursos de gente morta há tanto tempo, empresa das mais complicadas como, aliás, já havia observado um arguto filósofo da linguagem, o inglês Thomas Hobbes. Nos Elementos da Lei, livro de 1640, Hobbes já advertia sobre a opacidade dos textos antigos nos seguintes termos: "Ainda que as palavras constituam-se nos registros que nos restaram das opiniões e desejos dos outros, seus equívocos são tão comuns, de acordo com a diversidade de contextos e da companhia em que andam, que deve ser extremamente difícil descobrir as opiniões e o significado daqueles homens que se foram há muito tempo, e que não nos deixaram outro testemunho disso, a não ser os seus livros". ${ }^{23}$

Ao longo dos anos 1970, e no decorrer da década seguinte, o debate historiográfico acerca das teorias de interpretação dos textos políticos acabou por adquirir novos contornos, o que resultou no fortalecimento do contextualismo linguístico como corrente de vanguarda. Naquela quadra, Skinner persistiu na defesa de que a História do Pensamento Político deveria

22 SKINNER, Quentin. As fundações do pensamento político moderno. São Paulo: Companhia das Letras, 1996, p. 12s.

23 Citado por: GUNNEL, John. Teoria política, p. 67. 
ocupar-se com a reconstituição do sentido histórico das ideias. Tratava-se, portanto, de continuar descobrindo o que os pensadores políticos pretenderam dizer em seus textos. Para tanto, seria necessário recuperar as intenções de tais autores a partir da análise do contexto histórico de produção de suas obras, levando-se também em consideração os eventos e os debates travados frente às questões políticas formuladas em seu próprio tempo por outros agentes. Consultado dessa maneira, o texto do passado assumiria a dimensão de uma resposta consciente, como se tratasse de uma dimensão de ato linguístico, o que poderia revelar seu sentido quando focado em contraste com a sua época. Por essa perspectiva, a operação interpretativa consistiria “... em aprender a ler e reconhecer os diversos idiomas do discurso político da forma pela qual se encontravam disponíveis na cultura e na época em que o historiador está estudando". ${ }^{24}$ Segundo John Pocock, uma atitude como essa tornaria possível dominar o vocabulário normativo de autores do passado que, como testemunho de suas ideias e de seus programas de ação, legaram-nos apenas escritos embaçados pelos séculos. Acerca desse aspecto na análise dos textos antigos o próprio Skinner observa a questão da seguinte forma: “... quando falo da retórica hobbesiana do Leviatã, emprego essa palavra da maneira como o próprio Hobbes a entenderia, segundo creio. Dito de outro modo, utilizo-a para descrever um conjunto característico de técnicas linguísticas (...) derivadas das doutrinas retóricas da inventio, da dispositio e da elocutio, os três elementa principais das teorias clássicas e renascentistas sobre a eloquência escrita". ${ }^{25}$

Isso significa afirmar que a linguagem de Hobbes não é vidro transparente através do qual o pensamento do autor pode ser apreendido pelo leitor sem que se interponha entre ambos alguma interferência provocada pela ação deformadora dos tempos históricos. O argumento central de Pocock e de Skinner é o de que o domínio do vocabulário normativo que tanto descreve quanto legitima ações de personagens históricos permitiria ao intérprete compreender a linguagem na qual se expressou o autor do passado. Isso porque tal domínio possibilitaria estabelecer contato com a mensagem que um dado escritor político tentou transmitir para aqueles interlocutores que considerou como a sua audiência. Dessa forma, o vocabulário normativo poderá ser compreendido como o contexto linguístico, como a "vida" própria das palavras numa dada "instituição explícita de tempo" (expressão de Castoriadis), como as convenções muito específicas do processo de comunicação de uma dada cultura. Além do vocabulário normativo, será também preciso reconhecer o 
estilo retórico do qual o autor lançou mão para provocar, por exemplo, efeitos tencionados de ambiguidade. Ora, Hobbes camuflou algumas passagens, ou mesmo partes inteiras do Leviatã, com certos códigos retóricos, para poder falar, em tom menos ortodoxo e com um pouco mais de segurança, de temas como crenças religiosas e dogmas, verdadeiros campos minados nos meados do século XVII. E, mais ainda, num reino tomado pela guerra civil que, na essência, também era guerra de religião. Para alcançar seus objetivos, ele teve de "diluir" um pouco a verdade que pretendeu expressar em algumas metáforas mais palatáveis a seus leitores contemporâneos, para não sentir na própria pele os efeitos degradantes das masmorras ou de outros "expedientes extraordinários" (expressão de Maquiavel) normalmente utilizados contra a impertinência dos heréticos. Isso explica a defesa do emprego das assim chamadas "estratégias retóricas oblíquas". ${ }^{26}$

Ao se reconhecer os diferentes idiomas do discurso tornar-se-á possível ao historiador apreender o que o autor quis dizer. Como as ideias não se separam da linguagem, é sempre por um processo de incorporação da escrita do autor do passado que se ganharia o poder de pensar o que ele mesmo buscava pensar. Apesar das inúmeras limitações dos métodos de análise e de interpretação, a compreensão dos textos de autores antigos é uma operação intelectual possível, defende o historiador em tela. Para tentar reconstituir o sentido original de um texto político será preciso contrastá-lo com o contexto histórico em que foi produzido, procurando obter informações detalhadas acerca do grupo social do autor, a conjuntura em que escreveu sua obra, seus interesses intelectuais, seus engajamentos políticos, etc. Esse inventário de problemas historiográficos, esse questionário de dúvidas e de incertezas, da forma como aparece nos textos de Skinner, resume-se à seguinte indagação: o que escritores políticos como Maquiavel, como Hobbes ou, de uma maneira geral, como qualquer outro pensador político, "estavam fazendo" quando escreviam? Nesse gênero de pesquisa histórica trata-se, fundamentalmente, de empreender uma investigação para estabelecer os elementos de uma autoria que teve, num ponto circunscrito do passado, uma existência concreta, singular, datada, marcada por experiências geradoras do próprio texto. Assim procedendo, o contextualismo linguístico de Skinner acentua o poder que um autor do passado detém sobre sua própria criação, o domínio que ele tem de seus próprios pensamentos. Em vez dos conhecidos "significados privados" 
(expressão de Paul Ricoeur) ${ }^{27}$ — ou seja, aqueles sentidos subjetivos que são estabelecidos mais ou menos ao gosto do freguês, porque o discurso fixado no suporte "texto escrito" escaparia dos horizontes circunscritos das intenções autorais para tornar-se obra aberta nas mãos de leitores imaginativos Skinner pretende desvendar as singularidades estabelecidas no passado pela própria autoria. Para tanto, o historiador das ideias terá de percorrer o terreno cheio de obstáculos que é o tempo histórico, atravessar as suas camadas de diferentes densidades, para assim transpor a superfície do texto, o que significa que ele não deve se contentar com aquilo que o texto aparentemente diz quando apanhado fora de seu ambiente natural. Isso porque aquilo que um texto afirma ao leitor atual pode não coincidir, e frequentemente não coincide, com o que quis afirmar o autor. ${ }^{28}$

Esse modelo ou técnica de interpretação revela seu rigor, quero dizer, as suas propriedades positivas, na medida em que requer um conhecimento apurado das convenções linguísticas (ou vocabulário normativo), convenções que deram forma aos debates políticos do passado. Assim, não basta ler e interpretar as passagens mais complexas dos textos clássicos da Teoria Política, advertem os intérpretes contextualistas, meramente à luz dos próprios textos. É preciso ir além, porque é necessário que o historiador se familiarize com o sentido histórico das palavras e, por conseguinte, com o significado histórico das ideias. Para tanto, ele deve elaborar um questionário inicial de problemas que poderia partir de indagações como: o que tais ideias significavam no tempo em que foram concebidas, por que foram concebidas, de que forma foram utilizadas e que tipo de resultado efetivo pretendiam alcançar, ou seja, quais ações práticas tencionavam desencadear? Como já foi afirmado, a orientação teórica não mais deverá levar simplesmente ao "quê" estudar numa obra de pensamento. A questão bem mais relevante será "como" acercar-se de tais intenções porque raramente os mestres do passado lembraram-se de enunciálas com a clareza que gostaríamos. Para uma tal empresa, serão necessárias ferramentas, ou seja, instrumentos que se prestem ao inquérito histórico das ideias daqueles que só deixaram os seus textos como pálidos vestígios de sua passagem pelo mundo.

O que ao historiador das ideias resta fazer é seguir um "método" apropriado para compreender o sentido de uma linguagem que não é mais transparente.

27 Cf. RICOEUR, Paul. Interpretação e ideologias. Rio de Janeiro: Francisco Alves, 1990; e RICOEUR, Paul. Teoria da interpretação. Lisboa: Edições 70, 2000.

28 Cf. SKINNER, Quentin. "Meaning and Understanding in the History of Ideas. In: TULLY, James. (Org.). Meaning and Context. Quentin Skinner and his critics. Op. cit. 
Apesar de encoberto pelas camadas do tempo histórico, é possível distinguir o sentido escondido nos textos do passado. Ora, se os homens pensam e utilizam a linguagem de que dispõem no interior de uma dada cultura para expressar seus pensamentos, além de uma atividade linguística eles também realizam uma ação social. Se a linguagem é o meio para pensar e expressar sensações, sentimentos, vontades, atitudes, etc., esse processo ganha forma e realidade efetivas em um ambiente social. Então, ao dizer algo sobre o seu mundo histórico, o autor manifesta seu desejo de realizar algo, expressa sua vontade de atuar. O jargão técnico dos filósofos da linguagem a isso denomina por "atos de fala" ou "atos do discurso". Assim sendo, tentar distinguir as conexões das ideias políticas de um autor com o mundo histórico no qual elas foram geradas é parte de um esforço que poderá levar à reconstituição do sentido original de um texto.

Se os autores pensaram e expressaram suas expectativas por meio da linguagem em pleno curso de uma existência vivida em comum com outros indivíduos, descobre-se o que pensaram pela investigação daquilo com que se ocupavam no momento da elaboração do texto em estudo. A interrogação poderia ser assim formulada: o que Maquiavel estava fazendo quando escreveu $O$ Príncipe? Se for possível distinguir o "lugar de elaboração" dessa obra (expressão de Pocock), compreender-se-á coisas nebulosas como, por exemplo, o porquê de tal texto do historiador de Florença ser tão estranho aos mais autênticos valores políticos cultuados por ele mesmo. Ora, fica evidente a natureza bifronte do historiador florentino, pois o seu pensamento político não forma uma unidade, ainda que $O$ Príncipe e os Discursos sobre a Primeira Década de Tito Lívio tenham sido concebidos simultaneamente. Uma diferença tão gritante entre dois textos políticos de uma mesma lavra é um problema difícil e a coisa tornase ainda mais misteriosa porque não há nenhuma declaração esclarecedora por parte do autor acerca da bem mais do que aparente descontinuidade de seus projetos políticos em tais textos. Nesse ponto, a pesquisa de gênero também é um complemento importante da interpretação, porque alarga a via de acesso aos meios de expressão utilizados pelo autor. Com efeito, os espelhos de príncipes eram o gênero literário mais adequado para uma empresa como aquela tentada por Maquiavel em seu mais famoso livro.

Para concluir estas notas cabe dizer ainda que a tentativa de reconstituição do vocabulário normativo por meio do qual se expressaram os escritores políticos tornaria possível acessar o sentido original de uma obra de pensamento. Assim sendo, o propósito de uma interpretação histórica do texto político seria o de compreender os efeitos práticos gerados pelo exercício intelectual do autor, ou melhor, de esclarecer acerca de que tipo de ação um 
determinado autor pretendia desencadear a partir de ideias postas em circulação sob a forma de discurso político para "esculpir" esta ou aquela realidade. Para ele, acessar esse propósito seria possível colocando-se um discurso central em contraste com outros discursos, fossem de autoria do próprio autor ou mesmo de interlocutores que com ele estabeleceram relações. ${ }^{29}$ As relações intertextuais se configurariam assim como uma ferramenta eficaz no trabalho da interpretação e apreensão do sentido histórico das ideias. Para tanto, seria necessário cotejar documentos pessoais do autor em tela, ou textos de variada autoria, desde que entretecessem conexões com a obra escolhida como foco da análise. Como se referiu o próprio autor, “... a análise do contexto que abarca uma obra específica faz parte de um círculo hermenêutico muito mais vasto que a simples exegese do texto". ${ }^{30}$ Assim, para alcançar uma compreensão do sentido atribuído por Hobbes ao Leviatã não bastará ler e reler o Leviatã vezes sem conta. Será preciso ler o Leviatã confrontando-o com outros testemunhos deixados pelo próprio Hobbes. Mais do que isso, será adequado também comparar tais testemunhos com os registros de autores que viveram sob as mesmas circunstâncias de Hobbes. Skinner não deixa de observar a importância de analisar as reações dos contemporâneos ao pensamento de um autor de relevo. ${ }^{31}$ Tal atitude é recomendada não meramente para uma melhor compreensão do grande autor, mas para alargar o foco acerca da sua circulação e penetração em seu contexto, a forma como foram percebidas suas ideias, como foram admitidas e/ou recusadas. ${ }^{32}$

\section{Referências bibliográficas}

AUSTIN, John. How to do things with words. Oxford: Clarendon, 1962.

BLOOM, Allan. "Leo Strauss". In:_—_ Gigantes e anões. São Paulo: Best Seller, s.d.

29 "Todo meu trabalho é intertextual, isto é, trata de saber como e até que ponto o entendimento de um texto pressupõe o entendimento de sua relação com outros textos. Evidentemente, também tenho interesse por outro contexto, o político, já que ninguém escreve teoria política num vácuo". SKINNER, Quentin. Quentin Skinner. In: PALLARES-BURKE, Maria Lúcia. (Org.). As muitas faces da história. São Paulo: Editora Unesp, 2000 , p. 330.

30 "... the recovery of the historical meaning of any given text is a necessary condition of understending it, and this process can never be achieved simply by studying the text itself". SKINNER, Quentin. "Some Problems in the Analysis of Political Thought and Action". In: TULLY, James. (Org.). Meaning and Context. Quentin Skinner and his critics. p. 104.

31 "Nem sempre é suficiente estudar apenas as grandes obras. O que é fundamentalmente necessário para este tipo de exercício é lidar com o fantasma do relativamente obscuro, que preenche os intervalos entre os homens de gênio e que provavelmente são mais característicos da época". GREENLEAF, W. "Hobbes: o problema da interpretação”. In: —. QUIRINO, C.G. \& SOUZA, M.T.S. (Org.). O pensamento político clássico, p. 71.

32 Cf. SKINNER, Quentin. Razão e retórica na filosofia de Hobbes, p. 36. 
BOBBIO, Norberto. "Razões da filosofia política". In:——. Teoria Geral da Política: a filosofia política e as lições dos clássicos. Rio de Janeiro: Campus, 2000.

BOCARDO CRESPO, Enrique. (Org.). El giro contextual. Cinco ensayos de Quentin Skinner, y seis comentarios. Madrid: Editorial Tecnos, 2007.

BURKE, Peter. "A história social da linguagem". In:_—. A arte da conversação. São Paulo: Editora Unesp, 1995

BURKE, Peter. Montaigne. Oxford: Oxford University Press, 1994.

RIDLEY, Aaron. R.G. Collingwood. São Paulo: Editora Unesp, 2001.

DRAY, Willian H. "Michael Oakeshott's theory of history". In: ——. KING, Preston \& PAREKH, B.C. (Org.). Politics and Experience. Cambridge: Cambridge University Press, 1968.

GREENLEAF, W. "Hobbes: o problema da interpretação". In: —. QUIRINO, C.G. \& SOUZA, M.T.S. (Org.). O pensamento político clássico. São Paulo: T.A. Queiroz, 1992.

GUNNEL, John. Teoria Política. Brasília: Editora da UnB, 1981.

HARLAN, David. "A história intelectual e o retorno da literatura". In: RAGO, M. \& GIMENES, R. (Org.). Narrar o passado, repensar a história. Campinas: IFCH, 2000. HORTON, John. La filosofía política y la política. In: LEFTWICH, Adrien. (Org.). Qué es la política? México: Fondo de Cultura Económica, 1992.

HUISMAN, Denis. Dicionário dos filósofos. São Paulo: Martins Fontes, 2002. KERVÉGAN, Jean-François. "Leo Strauss". In: — . HUISMAN, Denis. Dicionário dos filósofos. São Paulo: Martins Fontes, 2002.

LASLETT, Peter. Apresentação. In: LOCKE, John. Dois tratados sobre o governo. Martins Fontes, 2001.

LASLETT, Peter. "Patriarchalism in Seventeenth Thinking. Filmer and his Contemporaries". In: —_. (Org.). Patriarcha and Other Political Works of Sir Robert Filmer. Oxford: Basil Blackwell, 1949.

MILLER, Eugene. "Leo Strauss". In: DE CRESPIGNY, Anthony \& MINOGUE, Kenneth. Filosofia Política Contemporânea. Brasília: Editora da UnB, 1982.

NIETZSCHE, F. "Fragmentos póstumos e aforismos". In: —. Escritos sobre História. Rio de Janeiro/São Paulo: Editora PUC-Rio/Edições Loyola, 2005.

OAKESHOTT, Michael. "The Activity of being an Historian". In:- - Rationalism in Politics and other essays. Londres: Methuen \& Co., 1967.

POCOCK, John. Introdução: o estado da arte. In: —. Linguagens do ideário político. São Paulo: Edusp, 2003.

POCOCK, John. "O conceito de linguagem e o métier d'historien". In: Linguagens do ideário político. São Paulo: Edusp, 2003.

RICOEUR, Paul. Interpretação e ideologias. Rio de Janeiro: Francisco Alves, 1990; e RICOEUR, Paul. Teoria da interpretação. Lisboa: Edições 70, 2000.

SKINNER, Quentin. "Motives, Intentions and the explanation of social action". In: TULLY, James. Meaning and Context. Quentin Skinner and his critics. Cambridge: Polity Press/Basil Blackwell, 1988. 
SKINNER, Quentin. "Some Problems in the Analysis of Political Thought and action". In: TULLY, James. Meaning and Context. Quentin Skinner and his critics. Cambridge: Polity Press/Basil Blackwell, 1988.

SKINNER, Quentin. "A liberdade e o historiador". In: —. Liberdade antes do liberalismo. São Paulo: Editora Unesp, 1999.

SKINNER, Quentin. As fundações do pensamento político moderno. São Paulo: Companhia das Letras, 1996.

SKINNER, Quentin. "Quentin Skinner". In: PALLARES-BURKE, Maria Lúcia. (Org.). As muitas faces da história. São Paulo: Editora Unesp, 2000.

SKINNER, Quentin. Razão e retórica na filosofia de Hobbes. São Paulo: Editora Unesp, 1999.

SKINNER, Quentin. Visions of Politics. Cambridge/UK: Cambridge University Press, 2002.

STRAUSS, Leo. The Political Philosophy of Hobbes. Its Basis and Its Genesis. Chicago: The University of Chicago Press, 1984.

TARCOV, Nathan. "Leo Strauss y la historia de la filosofía política". In: STRAUSS, Leo \& CROPSEY, Joseph. Historia de la filosofia política. México: Fondo de Cultura Económica, 1996.

TUCK, Richard. "História do pensamento político". In: BURKE, Peter. A escrita da História: novas perspectivas. São Paulo: Editora Unesp, 1992.

TULLY, James. (Org.). Meaning and Context. Quentin Skinner and his critics. Cambridge: Polity Press/Basil Blackwell, 1988.

WALSH, W.H. "The pratical and the historical past". In: — KING, Preston \& PAREKH, B.C. (Org.). Politics and Experience. Cambridge: Cambridge University Press, 1968.

WINOCK, Michel. “As ideias políticas”. In: RÉMOND, René. (Org.) Por uma história política. Rio de Janeiro: Editora FGV/Editora da UFRJ, 1996.

WOLIN, Sheldon. "Paradigms and Political Theories". In: —. KING, Preston \& PAREKH, B.C. (Org.). Politics and Experience. Cambridge: Cambridge University Press, 1968. 
